\title{
Computer-based interactive tutorial versus traditional lecture for teaching introductory aspects of pain
}

\author{
Mark I. Johnson, David G. Dewhurst and Alan D.Williams \\ School of Applied Sciences, Leeds Metropolitan University
}

In the health sciences, a wide range of computer-based courseware is now available. The aim of the study described in this paper has been to compare the effectiveness of a computer-based learning (CBL) software package and a traditional lecture (TL) for the delivery of introductory material on pain. Nineteen undergraduate nursing students were divided into two groups to attend a one-hour learning session which introduced clinical aspects of pain and which was delivered by either CBL or TL. Students were assessed for prior knowledge by a pre-session test, and for knowledge gain by an identical post-session test. In addition, a multiple-choice question paper was used to examine differences in pain knowledge between the two groups, and a questionnaire was used to examine the students' views on their experience during the learning session. The results demonstrated that both groups showed significant knowledge gain after their respective learning sessions. No significant differences between the groups in the magnitude of knowledge gain were found for clinical aspects of pain delivered during the learning sessions. The attitude questionnaire revealed that students attending CBL reported similar learning experiences to those attending the lecture.

\section{Introduction}

Pain is one of the most frequent complaints presenting to medical institutions. However, pain and its management continues to be marginalized in the content of health-care professional education due in part to the multi-disciplinary nature of the subject which makes it difficult to locate within the curriculum (Bonica, 1987; Liebeskind and Melzack, 1987; Marcer and Deighton, 1988; Pilowsky, 1988). Furthermore, the factual elements relating to pain often overlap with other parts of the curriculum, making it impossible to decide who should deliver the information, and how much time can be devoted within the limited time frame of normal health-care professional courses (Max, 1992). The International Association for the Study of Pain (IASP) core curriculum on pain education was developed to overcome some of these problems (Fields, 1995).

Traditionally the lecture has been considered as the most efficient and convenient method for disseminating information to health-care professionals. However, there are a number of 
inherent problems with the use of lecture-based education. In the biomedical and clinical science arenas there has been a large expansion in knowledge in the field and, as a consequence, educators are prone to try to deliver more and more information into their allotted time-slot in the course. Consequently, students are overloaded with information and lecturers do not allow students to develop the problem-solving skills which are essential in clinical reasoning (Barrows, 1983; Wilson et al, 1992). The widespread availability of computers and the development of a wide range of courseware mean that this need no longer be the case. Students engaged in computer-based learning (CBL) can control the pace of their learning and study independently with potential savings in staff time while achieving primary learning goals (Dewhurst et al, 1994). Moreover, it is important to employ a variety of educational methodologies to improve the learning experience of students and to reinforce facts. In this respect, $\mathrm{CBL}$ software packages are becoming a useful tool for modern-day medical students.

An interactive computer-based tutorial which aimed to introduce the clinical aspects of pain has been developed by ourselves (Johnson and Dewhurst, 1996) using Authorware Professional. The aim of the preliminary study presented in this paper was to evaluate whether the CBL program could adequately replace a traditional lecture (TL) on pain and its management.

\section{Methods}

\section{Subjects}

Nineteen undergraduate students (17 female, 2 male) at Leeds Metropolitan University participated in the study. The students were at Level (year) 2 of a four-year BSc (Hons) Nursing course, and had not received any previous formal lectures on pain or its management. However, the students had received a one-hour informal tutorial on psychological aspects of the pain experience and pain-assessment methods. All students were familiar with the use of CBL and had used a number of biomedical CBL programs at Level 1 of the course.

\section{Procedure}

Prior to the study, students were asked to identify their preferred mode of learning (lecture $\mathrm{n}=11 ;$ CBL $\mathrm{n}=8$ ). The class was then divided into two groups to attend a one-hour session of either CBL or TL. Only half of the students in the class were allowed to attend their preferred mode of study (CBL group preferred mode, $T L=5, C B L=4$; $T L$ group preferred mode, $\mathrm{CBL}=4, \mathrm{TL}=6$ ). The content of the lecture was identical to that of the CBL program. Students were assessed for prior knowledge by a 30 -minute pre-session test, and were told that they would be re-examined after the learning session. Students were allowed a coffee break after the learning session before they attempted to complete three post-session tests, viz: (i) a short answer examination (identical to the pre-test, although students were unaware of this fact); (ii) a multiple-choice question (MCQ) paper (20 questions); and (iii) an attitude questionnaire. 


\section{Tests of knowledge acquired}

Pre- and post-test examination paper

The pre-and post-test examination paper consisted of 10 short answer questions. Students were allowed 30 minutes to complete the paper which was subdivided into Section A (to assess student understanding of pain terminology) and Section B (to assess student understanding of clinical aspects of pain). Section A questions were:

1. Define pain

2. Define analgesia

3. Define pain threshold

4. What is a placebo?

5. What is the difference between the terms acute and chronic pain?

A maximum of two marks were assigned to each question (total of 10 marks), and all scripts were coded and marked blindly by the lecturer (MIJ).

Section B questions were:

6. List (name) as many painful conditions as you can

7. What components (aspects) of a patient's pain experience are useful for the medical staff to monitor?

8. Highlight some of the ways (methods) that you could use to assess a patient in pain

9. Outline how the body produces a sensation of pain when you stick your hand in a burning flame

10. List as many therapies as you can that are currently used to manage painful conditions

Questions 9 and 10 were not based on material delivered during the learning session and were included as controls. Questions 6 to 10 were marked by the lecturer (MIJ) using a side-by-side comparison of pre- and post-test scripts (blind) and identifying the best content-based answer. On breaking the code, a better post-test answer was assigned +1 in the data set, a better pre-test answer a -1 , and if both answers were equal in their content a value 0 was recorded. The results of the examinations were analysed by subtracting numerical scores for section $A$ of the pre-test short-answer questionnaire from post-test scores, group differences being determined using an unpaired t-test. Pre- to postdifferences for the whole group for section B were analysed using the Binomial Sign Test, and differences pre versus post between CBL and TL were analysed using the MannWhitney U Test.

Post-session multiple-choice paper

A 20-minute, 20-question multiple-choice paper was used to assess post-session differences in knowledge in a variety of basic and clinical aspects of pain between the two groups. Questions included a stem and a selection of 5 possible answers of which only one was correct. Examples of stems included:

Pain can be best described as...

Which of the following is NOT a characteristic of chronic pain ... 
Which of the following is NOT a descriptor associated with the SENSORY components of pain?

The basic means of pain assessment in the human is by. . .

Group differences in MCQ scores were analysed using an unpaired t-test.

Learning-session evaluation questionnaire

A questionnaire was used to evaluate the views of the students towards their learning experience during the session that they attended. The questionnaire consisted of 23 statements (see Appendix) and was administered immediately after the MCQ examination. Students were requested to rank their agreement or disagreement with statements using a 5-point Likert scale (Likert, 1932) using the following descriptors: Strongly agree $(+2)$, Agree $(+1)$, Neutral (0), Disagree $(-1)$, Strongly disagree $(-2)$. Differences in the median responses between the CBL and TL students were analysed using the Mann-Whitney Test.

\section{Material delivered during the learning session}

The learning session aimed to introduce students to general concepts of pain. The content of the CBL and TL were identical and delivered in the following order:

1. Introduction

2. Terminology (definitions of important terms e.g. pain, analgesia, allodynia, hyperalgesia, nociceptors)

3. Types of Pain (e.g. acute, chronic, nociceptive, neuropathic)

4. Functions of Pain (under normal physiological conditions)

5. Pain and Injury (the variable link between pain and injury)

6. Dimensions of Pain (sensory, affective, cognitive)

7. Pain Assessment (pain rating scales and pain location charts)

8. Pain Management (introduction to pharmacological and non-pharmacological methods of pain relief)

9. Summary

10. Revision (20 self-assessment MCQs).

The lecture was delivered by an IASP member (MIJ) using a combination of OHP transparencies (text and diagrams) and a whiteboard. Students were occasionally engaged by questions from the lecturer, although students were discouraged from asking questions until the end of the session. Students made notes during the lecture. The CBL program consisted of 10 sections, each containing a number of pages which combined descriptive text with high-resolution graphics. Features actively to engage the student - such as animation, a Hypertext facility, hangman games, drag-and-drop exercises, interpreting pain charts, completing statements, and multiple choice and true/false questions - were included in the program The CBL session was supervised by an IT specialist who was able to troubleshoot software and program navigational problems but was who was unable to advise on any specific aspects of the academic content of package. Students were instructed on the general aspects of navigation through the CBL package and were advised to examine the program Instructions for Use section before starting. 


\section{Results}

\section{Knowledge acquired}

Pre- and post-tests

No significant differences were observed between the groups in pre-test scores for section $A$ (pain terminology, mean $\pm \mathrm{SD}: \mathrm{CBL}=4.6 \pm 1.2 ; \mathrm{TL}=3.8 \pm 1.9 ; \mathrm{P}=0.29$, unpaired $\mathrm{t}$-test). There was a significant knowledge gain for section $\mathrm{A}$ between the pre- and post-sessions for the whole class (pre-test $=4.2 \pm 1.6$; post-test $=6.8 \pm 1.9 ; \mathrm{P}<0.01$, paired $\mathrm{t}$-test), and a significantly greater knowledge gain for students attending TL compared to CBL (increase pre- to post-test $\mathrm{CBL}=+1.4 \pm 2.3 ; \mathrm{TL}=+3.8 \pm 2.2 ; \mathrm{P}<0.05$, unpaired $\mathrm{t}$-test). There was a significant knowledge gain between the pre- and post-sessions for the whole class for Section B Q7 (P $\leq 0.01$, Binomial Sign Test) and Q8 (P $\leq 0.01)$, but not for Q9 and Q10 ( $P>0.05$, control questions) or $\mathrm{Q} 6(\mathrm{P}>0.05)$. $\mathrm{Q6}$ required students to name as many painful conditions as they could, and it is likely that the examples of painful conditions used during the TL and CBL were already familiar to the students. No significant differences in knowledge gain were observed between CBL and TL for any of the section B questions.

\section{MCQ paper}

There were no significant differences in post-session MCQ scores between CBL (15.8 \pm 1.6$)$ and TL (16.3 \pm 2.8$)$ students (mean $\pm S D ; P=0.62$, unpaired t-test). As no pre-test MCQ scores were obtained, it was not possible to determine whether there had been any knowledge gain.

\section{Student attitudes to the learning session}

Students from both groups expressed similar views towards their learning session (see Appendix). They agreed that they would recommend their session to colleagues interested in the subject (Q22), and that their session should be used again in future courses (Q21). They felt that the material in the CBL/TL was interesting (Q8), easy to follow (Q7), enjoyable (Q9), and they agreed that they gained much new information (Q15) and understanding of pain (Q16).

Significant differences were noted between the groups for Q3, Q17, and Q20 (Appendix). All 9 students attending the CBL session either 'strongly agreed' or 'agreed' that they were in control of their learning (Q3 median = 'strongly agree') compared to only 3 out of 10 TL students (median = 'neutral'; $P \leq 0.01$ ). This finding was supported by the results of an open-ended question where students reported that the 'best feature' of CBL was the ability to work through topics at their own pace, something which allowed them to spend more time on topics they found difficult ( $55 \%$ of responses). However, CBL students were allowed to use the program for only one hour. This may have compromised their ability to complete all the material, and may thus have contributed to the differences in knowledge gain between the groups observed in section A (pain terminology) of the short-question paper. $45 \%$ of CBL students stated that the 'best feature' of the program was its interactive properties which made them think through problems and allowed them to work at their own pace.

Eight out of ten TL students 'strongly agreed' that the lecture was a better way to learn than private reading compared to three out of nine CBL students (Q17, median response: $\mathrm{TL}=$ 'strongly agree'; $\mathrm{CBL}=$ 'agree'; $\mathrm{P} \leq 0.05$ ). Similarly, when comparing their learning session to a tutorial, seven out of nine TL students 'strongly agreed' or 'agreed 'that the 
lecture was a better way to learn than a tutorial. Only one out of nine CBL students 'agreed' that $C B L$ was a better way to learn than a tutorial $(Q 20, P \leq 0.01)$. However, the identical response distributions for Q15 and Q16 may indicate that students failed to differentiate between certain terms in the questionnaire, and it is possible that students applied a generic definition to the word 'learn'. The variations in student attitudes between the different methods of delivery of material therefore merits further examination.

\section{Discussion}

This study has demonstrated that CBL can be a useful adjunct to the delivery of educational material on pain. It is consistent in this respect with other studies in the area of biomedical science that attempt to replace or supplement existing teaching methods (Safrit et al, 1988; Garrett et al, 1990; Walsh and Bohn, 1990; Hollingsworth and Foster, 1991; Garrud et al, 1993; Napholz and McCanse, 1994; Stanford et al, 1994; Hutchins et al, 1995; Stehr-Green and Gathany, 1995; Gunn and Maxwell, 1996). Studies that oppose the view that CBL can replace existing methods include Garrett et al (1987). There has been much argument as to the validity of studies that take the experimental approach to evaluating the effectiveness of learning technology, and no firm conclusions have been drawn as yet, but Clark (1985a; 1985b) provides a thorough explanation of ways in which such studies may be confounded.

It was found that students attending a one-hour CBL session significantly gained in knowledge about pain when compared to their pre-session baseline. However, students attending the lecture showed a greater increase in knowledge acquired for basic pain terminology when compared to students attending the CBL session, although the magnitude of knowledge gain on other questions (e.g. Section B and MCQ) was comparable. Similar views about the learning experience were found between CBL and TL students, although TL students were more positive towards the role of traditional lectures when compared to private reading and tutorials than $C B L$ students were towards $C B L$. We suspect that students view CBL as a method to supplement rather than replace traditional lectures, a suspicion supported by Garrett et al (1987).

Students attending the CBL session appeared to be deficient in knowledge acquired for basic pain terminology (Section A). Subsequent to the study, we have found that, on average, it takes our nursing students two to four hours to thoroughly complete the CBL program. As students in the present study were given only one hour to complete it, it is likely that they will have quickly progressed through the entire program in an effort to observe all information rather than systematically attempting to answer problems from each section. Moreover, the lecture delivered a concentrated version of the material contained within the CBL program and it is likely that more emphasis was given by the lecturer to basic terminology. Napholz and McCanse (1994) suggest that CBL can reduce the time students need to learn specific content.

It is often perceived by lecturing staff that disseminating content-based material is achieved most quickly by lectures, although students often report that they are overwhelmed by the volume of material delivered. CBL students commented that the interactive properties of the CBL program enabled them to think through problems and allowed them to study at their own pace. The finding that students in the CBL group felt 
more in control of their learning is important. They reported that the best feature of CBL was the ability it gave them to spend more time on topics they found difficult. Students are more confident in their ability and consequently more enthusiastic about their learning when they feel that they are in control of the pace of their studies. Lectures ultimately dictate the speed of delivery of information and allow no flexibility for the wide range of student abilities within groups. Lecturers commonly encounter problems with students who fall behind due to an inability to assimilate difficult information quickly during the course of a lecture. With an ever-increasing range of student ability entering higher education, it is important to allow students to learn at a pace which is comfortable for them. As students have a greater access to computers, CBL programs will enable them to manage their own time. Furthermore, students quickly forget the factual elements of the curriculum after examinations and the reinforcement of facts is therefore an essential part of the learning experience (Levine and Forman 1973). CBL packages can be a useful and enjoyable revision tool.

A significantly greater proportion of TL students rated the session as a better way to learn than both private reading and a tutorial. This finding is interesting and suggests, once again, that students may see CBL as being more appropriate as tutorial material than as replacing the traditional lecture. Fincher et al (1988) have shown that medical students using CBL for the learning of electrocardiography performed significantly better than an equivalent group attending a weekly seminar on the subject for a six-week period. We currently use CBL as an independent study task to be completed outside formal teaching time and following one introductory lecture on pain. However, caution must be applied when interpreting the findings of our attitudes questionnaire. Although users' opinions and attitudes are routinely used to evaluate CBL, Jones and McCormac (1992) have shown that such criteria are poor evaluation tools as it can be difficult to standardize student interpretation of words used within the questionnaire. The identical response distributions for Q15 and Q16 (Appendix) may indicate that students have failed to differentiate between the terms 'information' and 'understanding', and it is likely that students applied a generic definition to the word 'learn' which encompasses a combination of gain in factual information, understanding and cognitive ability.

In general, the learning-session evaluation questionnaire revealed few differences in student views towards their respective learning experiences. This suggests that students are comfortable with CBL as a study aid, and students agreed that they would recommend CBL to colleagues interested in the subject. This is important, given an ever-increasing consumer-based student population who demand educational value for money. CBL students reported some problems associated with navigating through the program, and some students expressed concern that they might accidentally miss important information. Furthermore, some students expressed worry at the lack of lecture notes for future reference. Students attending the lecture reported that one of the best features of lectures was the ability readily to obtain these. A study guide incorporating printed lecture notes has been designed to accompany the CBL program in an attempt to overcome this problem.

In summary, this study has found that CBL can, generally speaking, be used effectively as an alternative to traditional lectures for the delivery of educational material on pain. 


\section{Acknowledgements}

The authors wish to express their thanks to Dr Paul Marchant for statistical advice, and Brett Bailey, Oliver Dawson and Natha Modhawadia who were involved in the design and development of the CBL software package.

\section{References}

Barrows, H.S. (1983), 'Problem based, self-directed learning', J.A.M.A., 250, 3077-80.

Bonica, J.J. (1987), Preface, Journal of Pain Symptom Management, 2, S3-S4.

Clark, R.E. (1985a) 'Confounding in educational computing research', Journal of Educational Computing Research, 1 (2), 137-148.

Clark, R.E. (1985b) 'Evidence for confounding in computer-based instruction studies: analysing the meta-analyses', Educational Communication and Technology Journal, 33 (4), 249-62.

Coleman, I.P., Dewhurst, D.G., Meehan, A.S. and Williams, A.D. (1994), 'A computer simulation for learning about the physiological response to exercise', American Journal of Physiology, 266 (11), S2-S9.

Dewhurst, D.G., Hardcastle, J., Hardcastle, P.T. and Stuart, E. (1994), 'Comparison of a computer simulation program and a traditional laboratory practical class for teaching the principles of intestinal absorption', American Journal of Physiology, 267 (12), S95-S104.

Fields, H.L. (1992), 'Core curriculum for professional education' in Fields, H.L. (ed), Pain (2nd edition), Seattle WA: International Association for the Study of Pain Publications.

Fincher, R.M.E., Abdulla, A.M., Sridharan, M.R., Houghton, J.L. and Henke, J.S. (1988), 'Computer-assisted learning compared with weekly seminars for teaching fundamental electrocardiography to junior medical students', Southern Medical Journal, 81, 1291-4.

Garrett, T.J., Ashford, A.R. and Savage, D.G. (1987) 'A comparison of CAI and tutorials in hematology and oncology', Journal of Medical Education, 62, 918-22.

Garrett, T.J., Selnow, G., Dobkin, J.F. and Healton, C. (1990) 'Computer-assisted instruction in AIDS infection control for physicians', Teaching and Learning in Medicine, $2,215-18$.

Garrud, P. et al (1993) 'Non-verbal communication: evaluation of a computer-assisted learning package'; Medical Education, 27, 474-8.

Gunn, C. and Maxwell, L. (1996), 'CAL in human anatomy', Journal of Computer Assisted Learning, 12 (4), 205-15.

Hollingsworth, M. and Foster, R.W. (1991), 'Computer-assisted learning (CAL) programs in drug disposition: replacement of lectures', British Journal of Pharmacology Proc. Suppl., $102,216 \mathrm{P}$

Hutchins, L. et al (1995), 'Evaluation of computer-based cancer education modules at the Arkansas Cancer Research Center', Journal of Medical Education Technologies, 6 (1), 4-9. 
Johnson, M.I. and Dewhurst, D.G. (1996), 'Clinical aspects of pain: a computer-based learning program to introduce the subject to undergraduate students', Journal of the Pain Society., 12, 71.

Jones, B.T. and McCormac, K. (1992), 'Empirical evidence shows that measuring users' opinions is not a satisfactory way of evaluating computer-assisted learning in nurse education', International Journal of Nursing Studies, 29, 411-25.

Levine, H.G. and Forman, P.M. (1973), 'A study of retention of knowledge of neurosciences information', Journal of Medical Education, 48, 867-9.

Liebeskind, J.C. and Melzack, R. (1987), 'The International Pain Foundation meeting for education in pain management' (Editorial), Pain, 30, 1-2.

Likert, R.A. (1932), 'A technique for the measurement of attitudes', Archives of Psychology, 140.

Marcer, D. and Deighton, S. (1988), 'Intractable pain: a neglected area of medical education in the UK', Journal of the Royal Society of Medicine, 81, 698-700.

Max, M.B. (1992), 'What should medical students learn about pain?' (Editorial), Pain, 50, 249-50.

Napholz, L. and McCanse, R. (1994), 'Interactive video instruction increases efficiency in cognitive learning in a Baccalaureate nursing education program', Computers in Nursing, $12(3), 149-53$.

Pilowsky, I. (1988), 'An outline curriculum for medical schools', Pain, 33, 1-2.

Stanford, W. et al (1994), 'Evaluation of a computer-based program for teaching cardiac anatomy', Investigative Radiology, 29, 248-52.

Stehr-Green, J. and Gathany, N. (1995), 'Pharyngitis in Louisiana: use of CBT to teach public health workers skills in outbreak investigation', Journal of Medical Education Technologies, 5(3), 14-18.

Walsh, R. and Bohn, R. (1990), 'Computer-assisted instructions: a role in teaching human gross anatomy', Medical Education, 24, 499-506.

Wilson, J.F., Brockopp, G.W., Kryst, S., Steger, H. and Witt, W.O. (1992), 'Medical students' attitudes toward pain before and after a brief course on pain', Pain, 50, 251-6. 


\section{Appendix}

A summary of student attitudes towards their respective learning session. Students ranked their agreement or disagreement with the statement according to Strongly Agree (SA), Agree (A), Neutral (N), Disagree (D), Strongly Disagree (SD). Values shown are the frequency of responses within each category. (CBL = students attending the computerbased learning session, $\mathrm{TL}=$ students attending the traditional lecture).

\begin{tabular}{|c|c|c|c|c|c|c|c|}
\hline Leam & ming session evaluation tool & $S A$ & $A$ & $N$ & D & SD & \\
\hline QI & The objectives were clear to me & 5 & $\ldots$ & 3 & 0 & 0 & $C B L$ \\
\hline Q2 & $\begin{array}{l}\text { Effective use was made of other forms of } \\
\text { presentation than merely verbal exposition (e.g. } \\
\text { diagrams, animation, questions with feedback) }\end{array}$ & $\begin{array}{l}8 \\
5 \\
3\end{array}$ & $\begin{array}{l}2 \\
4 \\
6\end{array}$ & $\begin{array}{l}0 \\
0 \\
1\end{array}$ & $\begin{array}{l}0 \\
0 \\
0\end{array}$ & $\begin{array}{l}0 \\
0 \\
0\end{array}$ & $\begin{array}{l}T L \\
C B L \\
T L\end{array}$ \\
\hline Q3 & $\begin{array}{l}\text { During the CBLlecture I was in control of my } \\
\text { learning }\end{array}$ & $\begin{array}{l}7 \\
1\end{array}$ & $\begin{array}{l}2 \\
2\end{array}$ & $\begin{array}{l}0 \\
7\end{array}$ & $\begin{array}{l}0 \\
0\end{array}$ & $\begin{array}{l}0 \\
0\end{array}$ & $\begin{array}{l}\text { CBL } \\
T L\end{array}$ \\
\hline $\begin{array}{l}\text { Q4 } \\
\text { inters }\end{array}$ & $\begin{array}{l}\text { The CBL/lecture involved a large amount of } \\
\text { craction }\end{array}$ & $\begin{array}{l}3 \\
4\end{array}$ & $\begin{array}{l}5 \\
5\end{array}$ & 1 & $\begin{array}{l}0 \\
0\end{array}$ & $\begin{array}{l}0 \\
0\end{array}$ & $\begin{array}{l}\mathrm{CBL} \\
\mathrm{TL}\end{array}$ \\
\hline Q5 & $\begin{array}{l}\text { The interaction during the CBLlecture was } \\
\text { active and stimulating }\end{array}$ & $\begin{array}{l}3 \\
2\end{array}$ & $\begin{array}{l}5 \\
8\end{array}$ & $\begin{array}{l}0 \\
0\end{array}$ & $\begin{array}{l}0 \\
0\end{array}$ & $\begin{array}{l}0 \\
0\end{array}$ & $\begin{array}{l}\text { CBL } \\
T L\end{array}$ \\
\hline Q6 & The diagrams were clear & $\begin{array}{l}5 \\
4\end{array}$ & $\begin{array}{l}4 \\
6\end{array}$ & $\begin{array}{l}0 \\
0\end{array}$ & $\begin{array}{l}0 \\
0\end{array}$ & $\begin{array}{l}0 \\
0\end{array}$ & $\begin{array}{l}\text { CBL } \\
T L\end{array}$ \\
\hline Q7 & It was easy to follow the CBL/lecture & $\begin{array}{l}2 \\
4\end{array}$ & $\begin{array}{l}6 \\
6\end{array}$ & 1 & $\begin{array}{l}0 \\
0\end{array}$ & $\begin{array}{l}0 \\
0\end{array}$ & $\begin{array}{l}\mathrm{CBL} \\
T L\end{array}$ \\
\hline Q8 & The CBL/lecture was interesting & $\begin{array}{l}3 \\
5\end{array}$ & $\begin{array}{l}5 \\
5\end{array}$ & 1 & $\begin{array}{l}0 \\
0\end{array}$ & $\begin{array}{l}0 \\
0\end{array}$ & $\begin{array}{l}\text { CBL } \\
T L\end{array}$ \\
\hline Q9 & I enjoyed the CBL/lecture & $\begin{array}{l}4 \\
3\end{array}$ & $\begin{array}{l}5 \\
7\end{array}$ & $\begin{array}{l}0 \\
0\end{array}$ & $\begin{array}{l}0 \\
0\end{array}$ & $\begin{array}{l}0 \\
0\end{array}$ & $\begin{array}{l}C B L \\
T L\end{array}$ \\
\hline Q10 & OI had sufficient background to follow the lecture & 2 & $\begin{array}{l}7 \\
5\end{array}$ & $\begin{array}{l}0 \\
3\end{array}$ & $\begin{array}{l}0 \\
0\end{array}$ & $\begin{array}{l}0 \\
0\end{array}$ & $\begin{array}{l}C B L \\
T L\end{array}$ \\
\hline Q11 & $\begin{array}{l}\text { I The learning objectives were fully covered by } \\
\text { the content of the CBL/lecture }\end{array}$ & $\begin{array}{l}2 \\
3\end{array}$ & $\begin{array}{l}1 \\
7\end{array}$ & $\begin{array}{l}4 \\
0\end{array}$ & $\begin{array}{l}1 \\
0\end{array}$ & $\begin{array}{l}0 \\
0\end{array}$ & $\begin{array}{l}\text { CBL } \\
\text { TL }\end{array}$ \\
\hline Q12 & $\begin{array}{l}2 \text { The CBL/lecture presented and explained the } \\
\text { material in an organised and systematic way }\end{array}$ & $\begin{array}{l}4 \\
6\end{array}$ & $\begin{array}{l}5 \\
3\end{array}$ & $\begin{array}{l}0 \\
0\end{array}$ & $\begin{array}{l}0 \\
0\end{array}$ & $\begin{array}{l}0 \\
0\end{array}$ & $\begin{array}{l}\mathrm{CBL} \\
\mathrm{TL}\end{array}$ \\
\hline Q13 & $\begin{array}{l}3 \text { The content of CBL/lecture was at the right } \\
\text { level for my needs }\end{array}$ & $\begin{array}{l}2 \\
6\end{array}$ & $\begin{array}{l}4 \\
3\end{array}$ & $\begin{array}{l}0 \\
1\end{array}$ & $\begin{array}{l}1 \\
0\end{array}$ & $\begin{array}{l}0 \\
0\end{array}$ & $\begin{array}{l}\mathrm{CBL} \\
\mathrm{TL}\end{array}$ \\
\hline Q14 & $\begin{array}{l}4 \text { The CBLlecture detected misunderstanding } \\
\text { or lack of knowledge on my part }\end{array}$ & $\begin{array}{l}1 \\
0\end{array}$ & $\begin{array}{l}4 \\
0\end{array}$ & $\begin{array}{l}1 \\
7\end{array}$ & $\begin{array}{l}3 \\
3\end{array}$ & $\begin{array}{l}0 \\
0\end{array}$ & $\begin{array}{l}\mathrm{CBL} \\
\mathrm{TL}\end{array}$ \\
\hline Q15 & $\begin{array}{l}51 \text { gained a lot of information from the } \\
\text { CBL/lecture }\end{array}$ & $\begin{array}{l}3 \\
2\end{array}$ & $\begin{array}{l}5 \\
8\end{array}$ & $\begin{array}{l}0 \\
0\end{array}$ & $\begin{array}{l}1 \\
0\end{array}$ & $\begin{array}{l}0 \\
0\end{array}$ & $\begin{array}{l}\mathrm{CBL} \\
\mathrm{TL}\end{array}$ \\
\hline Q16 & $\begin{array}{l}61 \text { gained a lot of understanding from the } \\
\mathrm{CBL} / \text { lecture }\end{array}$ & $\begin{array}{l}3 \\
2\end{array}$ & $\begin{array}{l}5 \\
8\end{array}$ & $\begin{array}{l}0 \\
0\end{array}$ & $\begin{array}{l}1 \\
0\end{array}$ & $\begin{array}{l}0 \\
0\end{array}$ & $\begin{array}{l}\text { CBL } \\
T L\end{array}$ \\
\hline Q17 & $\begin{array}{l}7 \text { The CBLlecture was a better way to learn } \\
\text { this material than private reading }\end{array}$ & $\begin{array}{l}3 \\
8\end{array}$ & $\begin{array}{l}3 \\
1\end{array}$ & $\begin{array}{l}2 \\
1\end{array}$ & $\begin{array}{l}0 \\
0\end{array}$ & $\begin{array}{l}0 \\
0\end{array}$ & $\begin{array}{l}\mathrm{CBL} \\
\mathrm{TL}\end{array}$ \\
\hline Q18 & $\begin{array}{l}\text { 8The CBL/lecture was a better way to learn } \\
\text { this material than a lecture/CBL }\end{array}$ & $\begin{array}{l}1 \\
2\end{array}$ & $\begin{array}{l}0 \\
2\end{array}$ & $\begin{array}{l}6 \\
5\end{array}$ & $\begin{array}{l}1 \\
0\end{array}$ & 1 & $\begin{array}{l}\text { CBL } \\
T L\end{array}$ \\
\hline Q19 & $\begin{array}{l}9 \text { The CBL/lecture was a better way to learn } \\
\text { this material than a practical }\end{array}$ & 1 & $\begin{array}{l}2 \\
1\end{array}$ & $\begin{array}{l}3 \\
6\end{array}$ & $\begin{array}{l}2 \\
1\end{array}$ & $\begin{array}{l}1 \\
0\end{array}$ & $\begin{array}{l}\mathrm{CBL} \\
\mathrm{TL}\end{array}$ \\
\hline Q20 & $\begin{array}{l}\text { OThe CBL/lecture was a better way to learn } \\
\text { this material than a tutorial }\end{array}$ & $\begin{array}{l}0 \\
1\end{array}$ & $\begin{array}{l}1 \\
6\end{array}$ & $\begin{array}{l}4 \\
1\end{array}$ & $\begin{array}{l}3 \\
1\end{array}$ & $\begin{array}{l}1 \\
0\end{array}$ & $\begin{array}{l}\text { CBL } \\
T L\end{array}$ \\
\hline Q21 & $\begin{array}{l}\text { II recommend that this CBLlecture be used } \\
\text { again in the course }\end{array}$ & $\begin{array}{l}4 \\
3\end{array}$ & $\begin{array}{l}2 \\
6\end{array}$ & 1 & $\begin{array}{l}0 \\
0\end{array}$ & $\begin{array}{l}1 \\
0\end{array}$ & $\begin{array}{l}\text { CBL } \\
T L\end{array}$ \\
\hline Q22 & $\begin{array}{l}21 \text { would recommend using this CBL/lecture } \\
\text { to students interested in the subject }\end{array}$ & $\begin{array}{l}4 \\
3\end{array}$ & $\begin{array}{l}4 \\
4\end{array}$ & $\begin{array}{l}0 \\
3\end{array}$ & $\begin{array}{l}0 \\
0\end{array}$ & $\begin{array}{l}1 \\
0\end{array}$ & $\begin{array}{l}C B L \\
T L\end{array}$ \\
\hline Q23 & $\begin{array}{l}3 \text { The } C B L / \text { lecture motivates me to study } \\
\text { further in some of these areas }\end{array}$ & $\begin{array}{l}5 \\
0\end{array}$ & $\begin{array}{l}1 \\
7\end{array}$ & $\begin{array}{l}2 \\
2\end{array}$ & $\begin{array}{l}1 \\
0\end{array}$ & $\begin{array}{l}0 \\
0\end{array}$ & $\begin{array}{l}\text { CBL } \\
\pi L\end{array}$ \\
\hline
\end{tabular}

